\title{
O sistema de crenças: aspectos qualitativos
}

\author{
Gilson Xavier de Azevedo* \\ Carolina Teles Lemos**
}

\section{Resumo}

O objetivo deste artigo revisional é analisar elementos conceituais a respeito sistema de crenças tratados nos artigos de Bousso (2010), Neufeld (2010), Pires (2013) e Velho (2011). Partindo de uma perspectiva das crenças religiosas, aborda-se depois o conectivo psicológico, que analisa as crenças humanas como resultado das emoções, o que é negado em alguns momentos da escrita deste artigo. Adota-se por metodologia um estudo exploratório do tema, objetivando aprofundar alguns aspectos pelo viés interpretativo. Estudar crenças é algo tão necessário atualmente como desenvolver pesquisa em qualquer campo científico, haja vista a influência que estas têm sobre o cotidiano de toda e qualquer estrutura. Mesmo sendo de revisão, o artigo estabelece um estado da questão, que permite alçar novas interpretações acerca do horizonte das crenças humanas.

Palavras-chave: Sistema. Crença. Sistema de Crenças.

\section{The system of beliefs: qualitative aspects}

\section{Abstract}

The objective of this review article is to analyze conceptual elements about belief systems treated in the articles of Bousso (2010), Neufeld (2010), Pires (2013) and Velho (2011). Starting from a perspective of religious beliefs, the psychological connective, which analyzes human beliefs as a result of emotions, is then approached, which is denied at some point in the writing of this article. An exploratory study of the subject is adopted by methodology in order to deepen some aspects by the interpretive bias. Studying beliefs is something as necessary today as developing research in any scientific field, given the influence it has on the everyday life of any and all structures. Although it is a revision, the article establishes a state of the issue that allows to raise new interpretations on the horizon of human beliefs.

Key-words: System. Belief. System of Beliefs.

\footnotetext{
* Doutor em Ciências da Religião pela PUC-GO (2014-2017-BOLSISTA FAPEG) (gilson.azevedo@ueg.br).

** Doutora em Ciências Sociais e da Religião pela Universidade Metodista de São Paulo (1998) (cetelemos@uol.com.br).
} 


\section{El sistema de creencias: aspectos cualitativos}

\section{Resumen}

El objetivo de este artículo revisado es analizar elementos conceptuales acerca del sistema de creencias tratados en los artículos de Bousso (2010), Neufeld (2010), Pires (2013) y Viejo (2011). A partir de una perspectiva de las creencias religiosas, se aborda después el conectivo psicológico, que analiza las creencias humanas como resultado de las emociones, lo que es negado en algunos momentos de la escritura destse artículo. Se adopta por metodología un estudio exploratorio del tema, con el objetivo de profundizar algunos aspectos por el sesgo interpretativo. Estudiar creencias es algo tan necesario actualmente como desarrollar investigación en cualquier campo científico, habida cuenta de la influencia que éstas tienen sobre el cotidiano de toda estructura. A pesar de ser de revisión, el artículo establece un estado de la cuestión, que permite alzar nuevas interpretaciones acerca del horizonte de las creencias humanas.

Palabras clave: Sistema. La creencia. Sistema de Creencias.

\section{Introdução}

Falar sobre sistema de crenças é, em algumas situações, aguçar um vespeiro de segmentos científicos, filosóficos e religiosos. Isso porque, ao lidar com tal conceito, toca-se necessariamente em questões como o que é realidade e o que é verdade. Todo sistema de crenças tem sua base numa percepção conjunta de um grupo de pessoas que pode ou não constituir uma verdade, ou antes, uma realidade.

Ao tocar na questão da verdade, não se pretende aqui estabelecer um tratado desse tema nem estabelecer um padrão de verdade, mas antes, basta notar que uma verdade para espartanos não deverá ser do mesmo modo que uma verdade para os atenienses. Isso se torna evidente ao recordar o conceito de educação para ambos os povos. Espartanos preparavam os seus filhos para a guerra e a defesa da cidade e essa era a sua educação, enquanto os gregos acreditavam na Paideia, na formação integral do homem envolvendo filosofia, arte e jogos.

Ao mesmo tempo em que a formação do sistema de crenças se mostra como natural, tal formação é tipicamente humana, pois envolve linguagem, matemática, artes, música, símbolos e representações. Tais elementos se fundem no que chamamos de educação, e conforme já tratei em outros artigos sobre o tema, a educação não é necessariamente a primeira estrutura que abriga e forma o sistema de crença humano. Também a cultura, como forma simbólica primeira, é construtora do sistema de crenças.

Conforme foi sinalizado, a religião, a filosofia e a ciência não se formam sem as crenças, e, tudo o que for afirmado pela manhã poderá ser 
negado à tarde. Assim, os valores e as crenças de uma geração, podem ou não serem aceitos pela geração seguinte, de modo que as informações que produzimos e recebemos diariamente têm um objetivo claro, que é o de estabelecer um parâmetro, uma verdade, uma alavanca (ARQUIMEDES) com a qual movemos nosso mundo e crenças.

\section{Articulando conceitos diversos}

Conforme se enunciou, as crenças podem ter origens diversas e estarem vinculadas a estruturas também distintas. Mesmo uma crença de origem irracional pode perfeitamente ser acolhida e mantida culturalmente por milhares de anos, como foi o caso da crença iniciada "cientificamente" por Ptolomeu, no século II d.C., de que a terra era o centro do universo e o sol girava em torno dela.

Mesmo no campo clínico, as crenças exercem forte influência sobre os indivíduos, tornando-se forças propulsoras de cura ou de morte, causando ora bem-estar, ora desconforto psíquico, chegando ao desenvolvimento patológico. "Se as crenças irracionais não forem descobertas e abandonadas, os pacientes muito provavelmente continuarão mantendo-as e desenvolvendo variações irracionais” (MATTA; BIZARRO; REPPOLD, 2009, p. 72).

As crenças podem manter os indivíduos na aparência de seguranças diversas. Por elas se crê que se vive muito, que se pode ser rico, que se está bem, que nenhum mal vai afligir o que crê, que os indivíduos são imbatíveis, amados, poderosos e empoderados. Pelas crenças, pressupõese a existência de "uma relação direta entre sua presença e a de fatores que representam sofrimento e desconforto psicológico". O inverso parece verdadeiro também, ou seja, “[...] é possível prever correlações inversas entre os elementos que predizem maior satisfação e conforto em relação à presença de um número significativo de crenças irracionais" (MATTA; BIZARRO; REPPOLD, 2009, p. 73).

Em geral, os indivíduos querem viver confortavelmente, chamam isso de paz, plenitude, felicidade, mas poucos pensam que tais sensações são um produto de uma ou de múltiplas crenças. "[...] as mudanças emocionais e comportamentais serão duradouras se resultarem da modificação de crenças disfuncionais básicas dos clientes" (NEUFELD, 2010). Essas crenças disfuncionais geram alterações psíquicas e físico-químicas por conseguinte. Os pensamentos automáticos do tipo: "posso morrer agora, ser atropelado, ganhar em determinado jogo" são os mais comuns e fazem parte de um 
"fluxo de processamento cognitivo subjacente ao processamento consciente. Geralmente, são particulares ao indivíduo e ocorrem de maneira rápida através da avaliação do significado de episódios de sua vida" (NEUFELD, 2010).

Outra forma de crença disfuncional são as crenças intermediárias formadas a partir de regras, atitudes ou suposições.

São afirmações do tipo 'se então' ou 'deveria' que se apresentam de modo inflexível e imperativo. Também podem ser chamadas de pressupostos subjacentes ou condicionais ou de crenças associadas. Estas formam um conjunto de crenças, em geral, coerentes que oferecem apoio às crenças centrais com as quais apresentam relação. [...] todas as pessoas têm um conjunto de crenças condicionais que foram aprendidas e somadas umas às outras ao longo da vida, no intuito de dar significado ao mundo (NEUFELD, 2010).

As crenças intermediárias são em geral causadoras de processos iniciais de formação de neuroses, mas podem atuar positivamente como elementos reforçadores da autoestima e da proatividade.

A terceira forma de crença disfuncional são as crenças centrais on nucleares; estas são desenvolvidas ainda na infância por meio de interações do indivíduo com outras pessoas também na vivência de ocasiões que fortaleçam uma ideia do tipo: "você é uma criança boa ou má, organizada ou desorganizada, querida ou rejeitada". Tais crenças podem ser formadas a partir de si, dos outros ou do mundo que cerca a pessoa. "As crenças centrais representam os mecanismos desenvolvidos pelas pessoas para lidar com as situações cotidianas, [...], sendo esta percepção chamada de tríade cognitiva" (NEUFELD, 2010).

Ainda para Neufeld:

[...] não são as crenças centrais em si que são disfuncionais, e sim sua forma de ativação que se torna disfuncional em alguns casos, quando esta não está condizente com o contexto e com as evidências. Desta maneira, de acordo com teoria dos modos, todos os indivíduos podem apresentar todas as crenças e estas não serem disfuncionais, até o momento em que sua ativação se torne disfuncional, quando o contexto e as evidências não derem base para aquela ativação (NEUFELD, 2010).

A forma como o indivíduo se vê é essencial para que ele consiga se olhar no espelho do outro e do mundo, encarar os problemas, entender seus sentimentos e os dos outros, valorizar e ser valorizado, elogiar e receber 
elogios. Caso isso não ocorra, entram em ação alguns tipos de estratégias cerebrais que compõem a inteligência emocional dos indivíduos e que lhes permitem sublimar os sentimentos negativos que ele mesmo construiu em sua psique.

Para o completo entendimento do sistema de crenças, faz-se necessário apresentar ainda o conceito de estratégias compensatórias. As estratégias compensatórias são comportamentos nos quais todos se engajam eventualmente. Estas ações causam sofrimento quando são executadas em excesso, em detrimento de outras estratégias mais funcionais (NEUFELD, 2010; grifos do autor).

Como foi visto, as estratégias compensatórias retroalimentam o sistema de crenças para favorecer a elevação das situações benéficas ao estado mental no mínimo favorável. Desse modo, buscou-se por meio da propositura de Neufeld (2010), visualizar elementos que permitam um olhar inicial, porém um pouco acurado sobre a relação entre saúde e crença. Propõe-se a seguir pensar a relação entre crença e existência, focando em específico as investigações de Bousso et al. (2011).

\section{Crença e existência em Bousso et al. (2011)}

O conceito de existência envolve uma série de pressupostos filosóficos religiosos que não se pretende tratar aqui. Para simples compreensão, a existência seria a tomada de consciência de que se está vivo e do que se está fazendo em razão de um objetivo pessoal.

No artigo que se propõe analisar agora, intitulado: "Crenças religiosas, doença e morte: perspectiva da família na experiência de doença”, foca-se especificamente naquilo que Bousso ${ }^{1}$ et al. (2011) chamarão de crença religiosa enquanto crença existência ou de um componente, no caso a religião, como forma de se explicar a doença e evocar a cura. "Para vários autores, as crenças religiosas e espirituais proporcionam possibilidades de significação e respostas às perguntas existenciais que se colocam diante da doença e possibilidade de morte" (BOUSSO et al., 2011, p. 398). Se for considerada a vida como um sentido e a morte como um fato contrário a isso, há que se cuidar da saúde como forma de se evitar a morte, de modo que a religião constitui uma crença de tal perpetuação.

\footnotetext{
Enfermeira. Professora Livre-Docente do Departamento de Enfermagem Materno-Infantil e Psiquiátrica da Escola de Enfermagem da Universidade de São Paulo. São Paulo, SP, Brasil.
} 
No entanto, ajudar pacientes e familiares a encontrar significados para suas experiências ainda se coloca como um desafio para os profissionais de saúde. Isso se deve, principalmente, porque os profissionais se sentem despreparados para lidar com as crenças religiosas e espirituais dos pacientes e familiares e, além disso, existirem poucos estudos que abordam este tema na literatura científica (BOUSSO et al., 2011, p. 398).

Se, por um lado, não é do sistema de crenças dos profissionais de saúde a questão religiosa, por outro, essa é corriqueira na vida dos enfermos. Sendo assim:

A religião oferece suporte emocional e social, motivação, recursos de cuidado à saúde e promove estilos de vida mais saudáveis. Neste sentido, os profissionais de saúde precisam conhecer as crenças que tornam o paciente e seus familiares mais, ou menos, dispostos a receber o tratamento (BOUSSO et al., 2011, p. 398).

Por meio da análise da afirmação, nota-se que a religião, como sistema de crenças, pode tornar-se aliada das crenças vinculadas ao campo da saúde e amenizar possíveis situações de sofrimento do paciente e familiares. Fora isso, a religião traz consigo princípios morais, de higiene e comportamento que facilitam a adoção de medidas de saúde.

As crenças podem ser adquiridas desde a concepção do indivíduo até a chegada da senilidade, mas podem ter origem e formações genéticas, originando cristalizações de crenças que aparecem em determinadas épocas da vida. Um exemplo de crença que se formou geneticamente é o consumo de chás ou alimentos que os avós ou os pais criam serem benéficos; tal propensão reaparecerá nas gerações futuras. Nos dois tipos de aquisição de crenças, nota-se que a crença permite ao indivíduo sentir-se seguro no mundo.

A religião é um instrumento de explicações que ajudam a dar significado às experiências de doença e morte. A espiritualidade, religiosidade, ou crenças religiosas mostram-se condutoras dos comportamentos dos familiares ao se moverem para um estado de adaptação e ajustamento à doença e morte. Acreditar que a vida não termina no momento da morte aparece nas narrativas como algo consolador, que permite uma melhor aceitação da morte. Rezar mostra-se como uma prática comum e confortadora no momento de dificuldade (BOUSSO et al., 2011, p. 400). 
No que fora citado, nota-se que a crença ocupa na mente o lugar de certeza ou verdade, mas, sem comprovações científicas, a crença permite o perfeito ajustamento da maneira como o indivíduo pensa e a forma como o mundo é.

Dentro das muitas formas de se justificar uma doença, crer que esta tenha sua origem em culpa pessoal, coletiva, familiar ou de ausência de hábitos saudáveis, agentes e fatos inesperados. Em todos esses casos, encontrar e aceitar como verdade um desses, satisfaz a maior e mais aguda necessidade humana que é a de estabelecer algo como verdade.

A religião impõe-se como a instituição social que controla os rituais e conhecimentos associados à morte. Ela não só oferece conforto nos tempos de sofrimento, mas também, pelo menos em algumas crenças, oferece uma promessa de vida após a morte e de reunião com a família perdida. As diferentes religiões e crenças oferecem à família diversas perspectivas da morte. Assim como a doença, a morte também foi associada a algo positivo ou negativo dependendo do tipo de crença daquele que vivencia a situação (BOUSSO et al., 2011, p. 401).

Essa tendência de se classificar algo como negativo afasta o indivíduo de sua aceitação em relação ao cosmo. Cita-se como exemplo os casos de suicídio que, para algumas religiões, tem-se como castigo a alma vagar eternamente sem descanso. Por sua vez, quando se encontra uma causa positiva do tipo: "Foi Deus quem quis, era a hora, foi melhor assim, descansou", a informação produzida no campo da crença satisfaz o indivíduo.

O indivíduo nunca deve ser compreendido como uma realidade autorreferente e autoexistente, mas como uma 'unidade complexa' que reflete o brilho dos processos sociais de uma sociedade complexa. A 'experiência significada' no ritual de interação torna-se um 'rito hermenêutico' de definição semântica do próprio sistema de crença do interagente (PIRES, 2013, p. 133).

Dentro do exposto, o indivíduo age, pensa, realiza as coisas que faz em seu cotidiano, mediante seu sistema de crenças. As crenças, mesmo não sendo verdades universais, movem o mundo, o cotidiano, a sociedade e as estruturas. Semelhante ao posicionamento de Bousso et al. (2011), Pires (2013), já citado, irá pontuar aspectos igualmente importantes na busca de se compreender "sistema de crenças", que este artigo dedica atenção a seguir. 


\section{Pires (2013) e o conceito de crenças}

A partir da leitura e reflexão do artigo: "Sistema de estruturação de crenças sociointerativo: Estruturação de crenças, lógicas de interação e processos de contingenciamento", nota-se em Pires ${ }^{2}$ (2013) que os estudos sobre o sistema de crenças não são novos, porém, a tentativa de sua sistematização é bem recente. O conceito perpassa a sociologia compreensiva e a antropologia estrutural, mas, conforme já indiquei em outros artigos sobre o tema, apenas a noção de sistema de crenças é nova, pois as crenças existem desde que o primeiro animal, seja ele humano ou não, pisou na terra.

A crença que se tinha [em Weber], e que ainda se tem hoje, é que a conduta humana é dotada de um caráter eminentemente "ativo e reflexivo" (ANTHONY GIDDENS), mas também "reativo" (MAX WEBER). Ela pode ainda ser passiva sem perder, com isso, a qualidade de coparticipante efetiva do movimento de qualquer atividade que caracterize a interacionalidade do indivíduo com uma realidade externa (PIRES, 2013, p. 134).

Como foi citado, as crenças ocupam não apenas um espaço, mas todo o espaço de nosso cotidiano e vida. Agimos, falamos e somos, segundo o que adotamos como verdade. A crença para Pires (2013) é, nesse sentido, um mecanismo dinâmico e multilateral, que permeia a existência humana como um todo.

Dentro do que fora afirmado, o agir humano parte primeiro de uma decisão, do latim decision, uma tomada de posição, uma crença que leva o indivíduo emocional e racionalmente a uma ação que produz reações diversas e adversas, dependendo de fatores como projeção, percepção e interpretação de outrem e até de quem age.

Depois, a fala também pressupõe um amplo universo de crenças. " $\mathrm{O}$ uso da linguagem está embutido nas atividades concretas da vida cotidiana e, num certo sentido, é parcialmente constitutivo dessas atividades" (GIDDENS, 2009, p. 17). Fala-se a partir do que se crê como verdadeiro, ou antes, do que se tem certeza como tal. A fala em si pressupõe uma interpretação da realidade,

2 Doutor em Sociologia pela Universidade Federal do Rio Grande do Sul (UFRGS) e doutor em Teologia pelo Programa de Pós-Graduação das Faculdades EST (PPG-EST), em São Leopoldo, RS. Professor visitante do Instituto Superior de Teologia Luterana. 
um óculos da razão ou das emoções $\left(\mathrm{Kant}^{3}\right)$ que falseia ou particulariza a realidade.

Linguagem é a comunicação significante que produz mobilidade inteligível dos agentes envolvidos na estrutura cognoscitiva de uma interação. A linguagem significante (mesmo aquelas que são destituídas de sintaxe) é o que torna possível o acesso compreensivo à lógica de cada ação com sentido (PIRES, 2013, p. 136).

Terceiro, o ser circunscreve um processo de autoconhecimento que pode ser verdadeiro, lógico, racional, ora emocional, afetivo, ancorado em traumas, forma de criação do indivíduo. Em todo caso, não se pode chegar a uma verdade unívoca sobre o que se é, apenas pode-se fazer deduções e aproximações, dadas as inúmeras possibilidades de se mudar o pensamento e o comportamento.

Em relação a esses três aspectos tratados, cita-se: "Contudo, a vida cotidiana deve ser concebida também como ação de inteligibilização da linguagem em movimento permanente, cuja natureza pode ser compreendida no sentido atribuído à racionalidade de cada ação manifesta" (PIRES, 2013, p. 136). Para o mesmo autor, "toda ação possui uma inteligibilidade intrínseca".

Nesse sentido, as crenças são construídas socialmente sempre a partir de uma perspectiva individual; trata-se de uma projeção que, segundo Pires (2013), envolve "ação, liberdade, linguagem, comunicação e inteligibilidade reativa". Na realidade, muitos outros fatores estão envolvidos em tal processo e cada processo de interação social envolve tipos diferentes e específicos de crenças. As crenças são um fenômeno humano por essência, dado o fato de que os indivíduos conseguem comunicar-se e serem entendidos por outrem, seja em qual língua for, o elemento simbólico, abstrato da linguagem está sempre presente.

3 Crenças (centrais) "são entendimentos que são tão fundamentais e profundos que as pessoas frequentemente não os articulam sequer para si mesmas. Essas ideias são consideradas pela pessoa como verdades absolutas, exatamente o modo como as coisas ‘são"' (BECK, 1997, p. 30). As crenças centrais acabam influenciando o desenvolvimento das crenças intermediárias, que consistem em atitudes, regras e suposições. Para Judith Beck (1997), as crenças são formadas a partir da relação estabelecida entre os indivíduos e o mundo no qual eles se encontram inseridos, e elas são consideradas "as lentes" a partir das quais eles interpretam as situações de vida. A crença, contudo, não pode ser confundida com o sentimento, ou com a emoção, ou memória apreendida, ou com a sensação (como fica sugerido em Rudolf Otto),1 mas possui uma estrutura psíquica na qual essas variáveis constituem parte de sua arquitetura ontológica (PIRES, 2013, p. 138; grifos do autor). 
Um sistema de estruturação de crença sociointerativo pressupõe a complexidade de fatores operacionais existentes que envolvem e compreendem os seguintes componentes expostos na sequência: ação, liberdade, linguagem, comunicação e inteligibilidade reativa. $O$ indivíduo deve ser concebido como agente (detentor de um poder de mobilidade) e sua agência deve ser dotada de potencialidade (liberdade para operar mudanças). Esses dois predicados presentes nele devem aparecer na estrutura de interação dos indivíduos, proporcionando-lhe um caráter inteligível de comunicação das necessidades existentes que possibilite a reação dos envolvidos nos processos de contingenciamento ou descontingenciamento (PIRES, 2013, p. 136).

Vale enfatizar que as ideias de mobilidade e potencialidade destacadas por Pires (2013) têm uma origem comum que é a crença de que se pode realizar algo.

A crença que se tinha lá [no passado], e que ainda se tem hoje, é que a conduta humana é dotada de um caráter eminentemente "ativo e reflexivo" (ANTHONY GIDDENS), mas também "reativo" (MAX WEBER). Ela pode ainda ser passiva sem perder, com isso, a qualidade de coparticipante efetiva do movimento de qualquer atividade que caracterize a interacionalidade do indivíduo com uma realidade externa (PIRES, 2013, p. 134). A coexistência de diferentes sistemas cognitivos tem sido variável fundamental para caracterizar sociedades modernas, distinguindo-as daquelas em que a predominância nítida ou quase exclusividade de um sistema sublinharia sua maior homogeneidade (VELHO, 2011, p. 1).

Parece ter ficado claro que a crença é de fato um fenômeno humano, e que, enquanto fenômeno, pode surgir socialmente na condição de individualidade ou de coletividade, sejam essas coercitivas ou não. Mencionase, por exemplo, entre tantos sacerdotes, figuras que ganharam a mídia como padre Marcelo Rossi e padre Fábio de Melo. Em meio a tantos indivíduos cometendo homicídios, destacam-se alguns serial killers. A educação seria uma crença coletiva na necessidade de se aprender determinado currículo. Nas formas coercitivas, citam-se os grandes ditadores e suas crenças de produzir um mundo puro e melhor.

\section{Sobre a psicologia do conceito de crenças em Pires}

Embora não se trate de um teórico do assunto, ressalto que a escolha de Pires (2013) para a análise que aqui se propôs, se justifica pela amplitude de seu artigo de revisão sobre o assunto, o que agrega valor ao que tenho 
proposto teorizar. Torna-se importante ressaltar que a crença sempre terá uma relação estreita com o "fenômeno psíquico"4 nos teóricos pesquisados por Bousso (2010), Neufeld (2010), Pires (2013) e Velho (2011).

Do ponto de vista fenomenológico, trata-se de uma disposição subjetiva na qual se figura a certeza intuitiva acerca da existência de algo ou de alguma coisa. A crença pode ser concebida como um 'condicionamento psicocognitivo' de acesso inteligivel e explicativo da vida, do mundo e das coisas existentes. Ela pode ser definida também como 'fundamento intencional do agir'. Inspirado pela antropologia estrutural de Lévi-Strauss, pode-se conceber a crença como uma forma de estrutura mental de acesso compreensivo à realidade. No idealismo transcendental de Kant, a crença aparece como um postulado ou certeza intuitiva da existência de coisas que não se pode demonstrar empiricamente, mas que se justificam ou podem ser inferidas de um tipo de decisão/escolha ética (PIRES, 2013, p. 138; grifos do autor).

Conforme o citado, parece importante ressaltar que a origem da crença é sempre individual, mesmo que se torne coletiva por alguma associação estrutural. Trata-se de uma disposição subjetiva, cognitiva, psicológica e intencional utilizadas para a interpretação e a interação com o que se crê como real. A crença é, portanto, uma ferramenta psíquica de natureza epistemológica que produz pensamentos e sentimentos. Nesse sentido, Weber busca em sua compreensão uma definição do conceito de crença como base de sua análise social:

Definir o que venha ser a crença não é uma tarefa fácil. Ela pode ser compreendida como uma ideia, uma representação mental, um postulado, uma estrutura cognitiva, um fato da razão, entre outras coisas. Max Weber foi o pioneiro da sociologia clássica a se interessar pela relação entre crença e comportamento (ethos). O "sentido subjetivo" visado pela análise de um

4 Skinner (2003). Admitir a existência de um sistema de crença flexível operando implicitamente no e por meio do comportamento humano é ir além da aparência dos movimentos meramente mecanicistas estabelecidos na relação entre "organismo e meio". O behaviorismo radical entende o comportamento humano (e dos outros organismos) como uma interação entre estímulos do ambiente e respostas do organismo. A Terapia Cognitiva transcende esse determinismo skinneriano e busca, na subjetividade humana (sistema de crença), um fator de compreensão e explicação do comportamento humano que é visceralmente variante. Esse achado da Terapia Cognitiva proporcionou o resgate da liberdade humana e da realização do indivíduo, o que no sistema teórico determinista da psicologia behaviorista, por causa da excessiva ênfase dada aos conceitos "controle e previsibilidade", havia sido completamente banido (PIRES, 2013, p. 141). 
comportamento/ação é o lócus onde a crença reside e se deixa deduzir na teoria weberiana. $\mathrm{Na}$ análise da ética religiosa, por exemplo, a compreensão dos postulados religiosos proporciona à apreensão do sentido que se quer obter do próprio comportamento religioso. A crença pode ser inferida de uma ação social de "modo racional referente a valores" (WEBER, 1994, p. 15).

Se, por um lado, os autores que se dedicaram a tratar o tema das crenças são unânimes a respeito de serem um fenômeno psíquico, por outro parece haver divergência com relação à racionalidade das crenças, justamente em relação ao aspecto religioso. Jung (2011), por exemplo, acredita que não se nasce com as crenças, já que os arquétipos (modelos de verdade) são construídos por meio da experienciação do mundo. Pode-se concordar com isso parcialmente, dado que crer, dar fé, esperar sobre a verdade de algo é uma característica humana.

A experiência de construção da crença, conforme se interpreta aqui, é de natureza social, pois ela implica a interação de "agentes envolvidos" numa teia de relação. Pontuar a experiência como matriz geracional de uma crença significa estabelecer um nexo causal de ligação entre eles (agentes envolvidos) de natureza interagente. Trata-se de um eu "em relação" a um tu. Nesse caso, considerando a natureza social que envolve a experiência de interagentes na geração de crenças, tal fenômeno se caracteriza também por seu movimento dialético próprio. Por sua estrutura interativo - geracional, as crenças são potencialmente reprodutoras (ativas) e reproduzidas (passivas). O aumento da complexidade de um sistema de crença origina-se aqui (PIRES, 2013, p. 142).

Assim, ao mesmo tempo em que se há de concordar com as citações feitas por Pires (2013) em relação ao fato de as crenças terem sua origem na coletividade, há que se recobrar o já exposto e considerá-las como causa das múltiplas visões de mundo que o humano constrói. Desse modo, as crenças nascem de maneira simples no indivíduo e à medida que ganham por sua generalidade, exterioridade e coerção (DURKHEIM) a coletividade, ganham complexidade. "Sua engenharia indica que ela (crença) assume uma identidade definida no processo dialético de comunicação/recepção/ interpretação do movimento dos interagentes envolvidos na relação" (PIRES, 2013, p. 144).

Pires (2013) define a crença em sua origem como um "rito hermenêutico" que determina o gênero de cada crença e faz que cada uma se prolifere. Desse modo, se a crença já é ou nasce de uma interpretação, 
por meio de novas interpretações ela se multiplica como distorção linguística (oxidante) ou como assentimento (alcalina ${ }^{5}$ ).

Sem o holofote hermenêutico da crença, nenhuma experiência vivida pode ser perfeitamente significada. Karl Mannheim pontua em sua Ideologia e Utopia (MANNHEIM, 2004) a existência de condicionamentos sociais presentes na produção do conhecimento. A identificação dos condicionamentos constitutivos do conhecimento é necessária para se alcançar a inteligibilidade da ordem que determinada racionalidade operante pertence. No sistema de funcionamento (psíquico) da crença, a identificação do seu gênero pode facilitar a compreensão do sentido das experiências de sociabilidade que o interagente viveu na diacronicidade de sua própria biografia. A inteligibilização é o objetivo interpretativo primário da identificação do gênero de uma crença. Por meio dela é possível ter acesso compreensivo à "ordem" da racionalidade vigente no sistema de funcionamento psíquico das crenças operantes do interagente (PIRES, 2013, p. 145).

Se considerado o conceito de Nomia em Durkheim como uma norma ou consentimento socialmente aceito, nota-se que a crença é o modus operandi da construção dessa norma, pois "a partir das crenças que se entende o modo como funcionam as coisas, a realidade social e os indivíduos em processo de acomodação no mundo da vida” (PIRES, 2013, p. 145).

A crença se torna um elemento simbólico maior e mais potente que a própria força física e existencial dos indivíduos, pois ela move tais "vontades de potência" (Nietzsche $e^{6}$ ); a crença motiva a ação, motiva a interpretação da ação, motiva a síntese e novamente gera uma nova tese, o pressuposto originário.

Essas novas teses, alavancas com as quais se move o mundo (ARQUIMEDES ${ }^{7}$ ) e por meio das quais a mudança continua (HERÁCLITO), tornam-se reais e o ser vai se fazendo continuamente em um eterno Dasein ${ }^{8}$

5 Pela própria acepção semântica do termo, se quer afirmar como gênero alcalino "crenças do tipo terapêutico". Seu gênero é reconhecimento por causa da função que elas operam. Por função (no sentindo operacional), as crenças alcalinas evidenciam uma dinâmica kalogeracional (kalos, do grego, significa "bom, benévolo, virtuoso, de agradável qualidade") no sistema de crença do interagente. Sistema, do grego sietemiun, significa, no modo mais comum da definição, um "conjunto de elementos interconectados" (PIRES, 2013, p. 146).

6 NIETZSCHE, F. W. Vontade de Potência. Trad. Mário D. Ferreira Santos. Rio de Janeiro: Ediouro.

7 "Dê-me um ponto de apoio, e moverei o mundo."

8 O ser em situação de existência. Ver em HEIDEGGER, M. Ser e Tempo: parte II, 2. ed. Trad. Márcia de Sá Cavalcanti. Parte II. Petrópolis: Vozes, 1998. 
(HEIDEGGER). Também promovem, como foi sinalizado por Pires (2011), um aumento de complexidade no ato de compreender o mundo que cerca o indivíduo. $\mathrm{O}$ aumento da complexidade do mundo é nessa ordem o aumento da complexidade das crenças que geram relações sociais mais complexas e padrões (nomos) comportamentais mais complexos.

O aumento da complexidade de um sistema está associado ao aumento de elementos/componentes existentes nele. Isso não significa dizer que o aumento da complexidade se apresenta com um potencial ameaçador à própria sobrevivência das crenças ou do sistema (PIRES, 2013, p. 145).

Mesmo os sistemas de crença mais complexos podem desenvolver padrões positivos de interação social. A questão da interação, parece se agravar quando se trata de sistemas deteriorados comuns em pessoas pessimistas e mal-humoradas, o que pode ou não estar acompanhado de padrões diversos de neuroses e TOC (transtorno obsessivo compulsivo). Não se pode, contudo, dizer que somos apenas nossas crenças, isso seria temerário, mas parece não haver dúvida entre os autores revisados que são determinantes da formação de emoções. Se o senso comum afirma que a "primeira impressão é a que fica", isso significa pensar que a crença individual é o padrão de aferição do comportamento do outro, de modo que se buscam semelhanças e diferenças ao se conhecer ou simplesmente ver alguém.

Se a crença individual serve para o "julgamento" de valor do outro, serve para a formação de uma visão da vida, do emprego, dos lugares que se frequenta, da família, da casa e do carro que se tem. O indivíduo depressivo provavelmente alimenta uma visão ruim, alterada, deturpada da realidade; trata-se de uma visão pessoal que nem sempre condiz com a realidade em que se vive. "As emoções e os sentimentos presentes em uma pessoa podem vitalizar o potencial oxidante (ou não) de uma crença operante capaz de perpetuar uma disposição ou sensação presente nela" (PIRES, 2013, p. 151).

Nesse caso, crença mostra-se paralela à memória, pois esta repetirá sentimentos em relação às pessoas, aos locais e às situações. Como já foi dito, se a impressão de alguém ou de algo foi ruim, é possível que continue ruim, não por ser de fato, mas porque a crença que se formou em relação àquela pessoa é repetida pela memória, independente da nova circunstância vivida. "Por essa razão, o sistema de crença dos interagentes nunca permanece inalterado na experiência de encontros significados. Crenças novas aparecem, 
e antigas são alteradas, vitalizadas ou mesmo substituídas" (PIRES, 2013, p. 153). Para Pires, os interagentes são agentes interativos, indivíduos capazes de modificar ou reprogramar ${ }^{9}$ racionalmente suas crenças. Tais indivíduos têm um maior controle das crenças sobre as emoções, ${ }^{10}$ podendo viver socialmente de forma menos impactante e mais estável.

Na memória se preserva ileso um sentimento ou uma sensação (pática ou hedônica), fazendo-a resvalar até a identificação de uma crença e sua inteligibilidade. Como os processos sociointerativos são determinados pela construção da trajetória biográfica de uma pessoa interagente, uma operação analítico-diacrônica, de acesso compreensivo ao sentimento presente na memória, pode levar à identificação de uma racionalidade sensitiva existente no subsolo da estrutura psíquica da crença (PIRES, 2013, p. 152).

Embora se acredite (PIRES, 2013) que as experiências também geram crenças, é mais plausível pensar que somente crenças geram outras crenças. Se, por um lado, não há nada na mente que antes não tenha passado pelos sentidos, (ARISTÓTELES), há que se considerar, que mesmo não havendo "nada", ainda há algo, ou seja, a própria mente (HUME) como a verdadeira matriz geradora de crenças. Para Giddens as: "condições governando a continuidade ou a transmutação de estruturas e, portanto, a reprodução de sistemas sociais" (GIDDENS, 2009, p. 29). Isso significa dizer que situações motivam crenças, mas que o inverso é igualmente verdadeiro.

As crenças definem o sentido da ação de uma pessoa interagente. A identidade desta é definida pelo seu sistema de crença. O que é uma pessoa? Ela é o seu sistema de crença operando em lógicas de interação no mundo da vida humana. O comportamento, enquanto ação imbuída de sentido e intenção, não pode ser compreendido do ponto de vista estritamente mecanicista, biologizante (PIRES, 2013, p. 155).

\footnotetext{
9 A reestruturação de crenças, contudo, tem que ser compreendida como uma nova oportunidade hermenêutica de reler situações (novas ou antigas) e se reler a própria vida nelas, por intermédio delas e a partir delas em um momento compreensivo que pressupõe maior maturação cognitiva do interagente. No estágio hermenêutico da reestruturação de crenças, novas experiências enviesadas por crenças revisitadas/redefinidas podem ganhar um sentido dialético com maior efeito terapêutico para a estrutura de relação dos próprios indivíduos/interagentes (PIRES, 2013, p. 155).

10 A própria construção de paradigmas como mostra, por exemplo, Victor Turner (1974) se dá em um processo em que as crenças estão indissoluvelmente associadas a emoções socialmente reconhecidas e valorizadas. A noção de eficácia simbólica, por sua vez, baseiase na capacidade de envolver indivíduos e grupos de uma forma totalizante (VELHO, 2011, p. 5).
} 
Note o leitor que o discurso de Pires (2013) tende quase que exclusivamente para o campo da compressão psicológica, conforme foi sinalizado no início do artigo. Não obstante, "Parece ser precipitado igualar uma sociedade a um sistema cognitivo. Este pode atravessar ou abranger diversas sociedades e uma destas, por sua vez, pode estar ancorada a mais de um sistema" (VELHO, 2011, p. 1).

Estabelecer um padrão comportamental a partir do sistema de crenças também se mostra como algo temerário, dado que Velho (2011) compreende o fator crença como um fator individualizante, que torna único o indivíduo, ainda que esse pense como outros e pertença a uma coletividade. Velho no entanto, destaca que "a noção de sistema cognitivo é indissociável de sistema de crenças, e este, por sua vez, implica imediatamente em emoção, sentimento" (VELHO, 2011, p. 2).

Geertz distingue a visão de mundo de ethos enquanto Bateson diferenciou eidos de ethos. Grosso modo, a ênfase nos aspectos cognitivos recai em visão de mundo e eidos enquanto ethos estaria associado a estilo de vida, aspectos afetivos, estéticos, etc. Estou aproximando Geertz de Bateson sabendo que há grandes diferenças em suas abordagens mas em ambos, de alguma maneira, a dimensão cognitiva é dissociada de outras dimensões ou variáveis (VELHO, 2011, p. 2).

Nesse caso, não é o estilo de vida que parece determinar a crença, mas o inverso. Pensar sistema de crenças do ponto vista psicanalítico é algo que exige muita atenção, cuidado e tato conceitual, mas é também inevitável se o desejo for ampliar tal conceito. Acredita-se que a análise das considerações de Pires (2013), perpendiculadas pelas intervenções de Velho e Giddens, permitiu estabelecer alguns parâmetros conceituais do universo vasto que é o sistema de crenças.

\section{Considerações finais}

A temática sistema de crenças tem sido nos últimos anos recorrente em revistas que abrem dossiês ligados à psicologia e ciências da religião. Neste artigo, tratou-se da concepção religiosa como uma crença e um sistema essencial à manutenção do estado existencial e psíquico dos indivíduos em seu cotidiano. Já que as crenças, mesmo religiosas, envolvem a dimensão psíquica, buscaram-se outras fontes que pudessem ampliar a concepção de crenças como origem da construção emocional dos sujeitos, determinando 
por vezes a noção de realidade que cada indivíduo carrega consigo e forma a noção de coletividade (nomia).

Acredita-se que o artigo seja relevante para a discussão em torno do universo das crenças, para uma maior elucidação conceitual das mesmas, de modo a se abrir espaço de discussão profícuo para então se entender melhor como elas atuam em nossa mente determinando o pensar e o agir humano.

\section{Referências}

BOUSSO et al., Regina Szylit et al. Crenças religiosas, doença e morte: perspectiva da família na experiência de doença. Rev. esc. enferm. USP, São Paulo, v. 45, n. 2, p. 397-403, Apr. 2011. Disponível em: http://www.scielo.br/scielo.php?script=sci _arttext\&pid=S008062342011000200014\&lng=en\&nrm=iso. Acesso em: 28 jun. 2017.

GIDDENS, A. A constituição da sociedade. São Paulo: Martins Fontes, 2009.

HEIDEGGER, M. Ser e Tempo: parte II, 2. ed. Trad. Márcia de Sá Cavalcanti. Parte II. Petrópolis: Vozes, 1998.

MATTA, A.; BIZARRO, L.; REPPOLD, C. T. Crenças ir racionais, ajustamento psicológico e satisfação de vida. Psico-USF, v. 14, n. 1, p. 71-81, jan./abr. 2009, p. 71-81.

NEUFELD, Carmem Beatriz; CAVENAGE, Carla Cristina. Conceitualização cognitiva de caso: uma proposta de sistematização a partir da prática clínica e da formação de terapeutas cognitivo-comportamentais. Rev. bras. ter. cogn., Rio de Janeiro, v. 6, n. 2, p. 3-36, dez. 2010. Disponível em: http://pepsic.bvsalud.org/scielo.php?script=sci_arttext\&pid=S180856872010000200002\&lng=pt\&nrm=iso. Acesso em: 28 jun. 2017.

NIETZSCHE, F. W. Vontade de Potência. Trad. Mário D. Ferreira Santos. Rio de Janeiro: Ediouro.

PIRES, Anderson Clayton. Sistema de estruturação de crenças sociointerativo: Estruturação de crenças, lógicas de interação e processos de contingenciamento. Psicol inf., São Paulo, v. 17, n. 17, p. 133-191, dez. 2013. Disponível em: http://pepsic.bvsalud.org/scielo.php?script=sci_ arttext\&pid=S1415-88092013000200010\&lng=pt\&nrm=iso. Acesso em: 26 jun. 2017.

VELHO, G. Sistemas cognitivos e sistemas de crenças: Problemas de Definição e Comparação. XIII Reunião Brasileira de Antropologia, USP, abril de 1982. Publicado em Comunicação nº. 8, PPGAS/Museu Nacional-UFRJ, 1984, 21 jun. 2011.

Submetido em: 18-7-2017

Aceito em: 27-11-2018 